\title{
Religion as an Alleviating Factor in Iranian Cancer Patients: a Qualitative Study
}

\author{
Mozhgan Rahnama1, Masoud Fallahi Khoshknab'*, Sadat Seyed Bagher \\ Maddah $^{2}$, Fazlollah Ahmadi ${ }^{3}$, Azizollah Arbabisarjou ${ }^{4}$
}

\begin{abstract}
After diagnosis of cancer, many patients show more inclination towards religion and religious activities. This qualitative study using semi-structured interviews explored the perspectives and experiences of 17 Iranian cancer patients and their families regarding the role of religion in their adaptation to cancer in one of the hospitals in Tehran and a charity institute. The content analysis identified two themes: "religious beliefs "(illness as God's will, being cured by God's will, belief in God's supportiveness, having faith in God as a relieving factor, and hope in divine healing) and "relationship with God during the illness." In general, relationship with God and religious beliefs had a positive effect on the patients adapting to their condition, without negative consequences such as stopping their treatment process and just waiting to be cured by God. Thus a strengthening of such beliefs, as a coping factor, could be recommended through religious counseling.
\end{abstract}

Keywords: Religion - neoplasm - culture - qualitative research - Iran

Asian Pac J Cancer Prev, 16 (18), 8519-8524

\section{Introduction}

As a bitter fact and a stress inducing factor, today chronic diseases - such as cancer - have affected millions of lives (Montaseri and Sharif, 2008). According to the predictions of the World Health Organization (WHO), the year 2000 figure of 10 million people suffering from cancer will reach 15 million by 2020 . This organization has further forecasted that cancer-related mortality will reach 9 million by 2015. In Iran, annually, 70,000 people get cancer and 30,000 people die from cancer (Heiydari et al., 2008).

The disease cancer is defined by individuals as a complex situation during which a kind of stress produced by a threat to their needs is felt by them. Once a need is threatened, mobilization of resources is required for adjustment and adaptation (Ebadi et al., 2009). Generally, the key point about the induced stress is the way of responding or reacting to the illness, which could play a significant role in the individual's adaptation. This point has been focused upon in this research under the title of coping strategies (Nasirzadeh and Rassolzadeh Tabatabaie, 2009).

Cancer diagnosis influences the overall life of individuals (Rustøen et al., 2003). It changes their way of life, causes many physical, mental, social, economic and family problems, and creates a feeling of dependability, low self-confidence and a strong sense of susceptibility.
Physical and mental symptoms such as dizziness, pain, confusion, etc. become evident in most patients. The illness interrupts the individual's daily functions, social activities, and peace of mind, and instead creates new issues for them (Heiydari et al., 2008). Krause et al. (1991) claimed that when cancer patients are informed of their illness, they respond to it through defense mechanisms that manifest themselves in intensely agitated reactions and curtails in their making a reassessment of their lives with the aim of adapting to the new conditions at hand (Rustoen et al., 2003).

Although during the past three decades, several studies have been conducted on stress and adaption, only recently researchers have developed an interest in the realm of religion and spirituality as a possible source for individuals to apply when dealing with stress-inducing events in their lives (Lynn Gall and Cornblat, 2002). Similarity, Ebadi et al found spirituality to be a key factor for the acceptance and adoption of chronic diseases among the participants. They also stated that spiritual adaptive strategies help people find meaning and goals during their illness (Ebadi et al., 2009). Arian (2001) investigated the relationships between piety and components of mental health, and reported a positive and significant correlation between satisfaction and pleasure, on the one hand, and religion, on the other. He further recorded a negative correlation between piety and depression (Rohani and Manawi pour, 2009). Muller et al reported in their review

${ }^{1}$ Department of Nursing, Zabol University of Medical Sciences, ${ }^{2}$ Department of Nursing, University of Social Welfare and Rehabilitation Sciences, ${ }^{3}$ Department of Nursing, Faculty of Medical Sciences, Tarbiat Modares University, Tehran, ${ }^{4}$ Zahedan University of Medical Sciences, Zahedan, Iran *For correspondence: ganjresearch@gmail.com 
study that most researches have shown that spiritual and religious involvements are related to the positive results of health care as well as to a more efficient use of adaptive skills, and a decrease in anxiety, depression and suicidal tendency(Mueller et al., 2001). Kurtz et al. (1993) reported that the development and maintenance of a spiritual perspective toward health could be a master key to longterm adaption with cancer. In addition, Paragment (1992) and Jenkis \& Paragment (1995) suggested that religious and spiritual factors can influence the way in which the individual interprets, evaluates and, finally, chooses an approach to deal with a stressful event such as cancer (Lynn Gall and Cornblat, 2002) However, along with these studies, which suggest that religion and spirituality can be accompanied with better adoption and mental health, some other studies highlight the negative effects that religion and spirituality can have on a patient's health due to the creation of a sense of fatalism. Fatalism can be defined as a belief that the outcome of health is controlled by faith, God or gods. This kind of belief can serve as a major obstacle in the patients' participation in selective studies and, as a hindrance, in treatment plans (Harandy et al., 2009). Fatalism in cancer can create a sense of disappointment, powerlessness, insignificance and /or even social despair. In a research conducted on colorectal cancer patients in 1997, Powe showed that fatalistic perception led to a low participation of individuals in the research work. Powe further reported that this perception not only eliminated hope in the individuals diagnosed with cancer, but also it inhibited the individuals' efforts to cope with the disease (Powe, 1997). Also Paragment (1997) concluded that $24 \%$ of the 130 studies reviewed indicated a positive relationship between religious confrontation, on the one hand, and adaptation and mental health, on the other, while only $4 \%$ of them showed a negative correlation. However, $62 \%$ of the above researches reviewed did not report any relationship among these parameters (Nasirzadeh and Rassolzadeh Tabatabaie, 2009).

Thus it can generally be agreed that there is a kind of ambiguity regarding the positive or negative effects religion have on the adaption process of cancer patients. Moreover, since firstly the experiences of patients and their families could be a basis for clarifying the nature of these effects, and secondly the perception of these effects could be influenced by an individual's beliefs and culture, and thirdly Iranian patients could perceive the same case differently compared to patients from other cultures, the seeking of a better understanding of the role of religion was necessitated. This study was conducted with the aim of investigating the perception of cancer patients and their families regarding the role that religion plays in adaption to cancer.

\section{Materials and Methods}

\section{Design}

In this qualitative research, content analysis approach was used to explore the perspectives and experiences of Iranian cancer patients and their families regarding the role of religion in their adaptation to cancer.

\section{Participants}

The participants of this study consisted of 11 cancer patients from one of the hospitals and a charity institute for cancer patients in the city of Tehran and 6 of their family members. Sampling was conducted based on an purposive method. In order to achieve maximum variation of data, the participants chosen included patients with a wide range of characteristics (age, gender, socio-economic status and illness phase).

\section{Data collection}

Data gathering was done by face-to-face semistructured interviews from September 2010 to March 2011. First, general questions were asked at the beginning of the interviews and, later the tempo of the interview was followed based on the interviewees' responses. The major focus of the questions in the interviews was: "What is your perspective about the role of religion in your adaptation to cancer." In addition, probing questions were asked to follow the participants' thoughts and to bring clarification to their responses during the interview. Time and location of the interviews were agreed upon with the participants. Each. The data collection process continued until data saturation was reached and, finally, two main themes emerged.

\section{Data analysis}

All interviews were conducted, recorded, transcribed verbatim, reviewed, coded, and immediately analyzed by the first researcher. First, each interview was read precisely to attain a general understating and the important points were underlined and recorded as codes (initial coding). The words used by the participants made up the initial coding whereas the implicated codes were formed by what was understood by the researcher. Next, the conceptually similar codes were further refined to promote clarity and then classified into categories and sub-categories.

\section{Rigour}

The reliability and validity of this research were examined using the criteria suggested by Gouba and Lincoln (Strubert Speziale et al., 2003). The credibility of the study was enhanced through establishing sufficient cooperation and interaction with the participants, reviewing interviews by the participants and other guides, and using complementary comments of professors. The researcher examined the data dependability through reviewing the related works and making discussions with the guides, consultants and specialists. Further, the confirmability of the data was checked by discarding presumptions and prejudices made by the researcher, and the participants were asked about their opinions regarding the consistency of the data.

\section{Ethical considerations}

The study was conducted after taking the approval of the Ethics Committee (code:500-205). The permission to conduct the study in the research environment was also acquired. In this research, the participants were given information regarding the dimensions of the 
research. They were further ensured that all their personal information would be kept secret during the publication of results and that they had the right to withdraw from the study at any time they wished.

\section{Results}

The participants of this study consisted of 17 participants including: 11 cancer patients who were being treated at a hospital and one of the special charity institutes for cancer patients in Tehran and 6 members of the patients' families. The patients' ages varied from 27 to 65 years while the age range of their family members was between 24 and 60 years. Six of the patients participating in this study were females and 5 were males, and all the participating family members were females. The types of carcinoma of the participants were: breast cancer, intestinal cancer, liver cancer, spinal cord tumor, brain tumor, lung cancer and testicular cancer. In terms of treatment phase, all patients had undergone surgery; 4 were undergoing chemotherapy, 4 were subject to radiotherapy and 3 were at the recovery period of at least 1 year after their last treatment course. The goal of this study was to investigate the perception of the cancer patients and their families with regards to the role of religious beliefs in their adaption to the disease. The findings of this study illustrate the patients' religious beliefs about God, the causes of their illness, recuperation, and relationship with God during the illness.

\section{Religious beliefs}

This theme included the sub-themes of "Illness as God's will”, "Being cured by God's will”,

"Belief in God's supportiveness", "Having faith in God as a relieving factor" and "Hope in divine healing".

\section{Illness as God's will}

In the interviews with the participants, it was found that a number of them believed that their illness had occurred due to God's will, but they mentioned different reasons for this will of God. For instance, some of them supposed that their illness was a punishment for their sins:

"Sometimes, I say: Oh God, I'm sure I've done something wrong and this is my own fault that You have given me this illness, or else You don't wish bad things for Your creatures." (36 years old female patient)

They did not have an ill-feeling about this will of God; since, they believed that God cleanses them through such an ailment: "During the chemotherapy, I experienced a lot of pain but I am not displeased about it because I think when people suffer pain, God forgives their faults." (45 years old female patient)

Also some participants assumed their illness as a favor from God. They believed that they had forgotten God, but through the illness, they have been drawn closer to Him. They believed that the illness had offered them another chance to be closer to God:"Last year I went through 12 chemotherapy sessions. Maybe after all those sessions, I still hadn't become the ideal person I should; yet God gave me another chance. Though it is along with an illness, I am
Religion as an Alleviating Factor in Iranian Cancer Patients

not sad because my relationship with God had weakened and, by giving me this illness, He gave me another chance to return to Him." (33 years old male patient)

"The illness seems like a disaster at the first sight, but indeed it is one of God's favors bestowed upon us. It makes us more alert and makes us remember Him." (50 years old female family member)

Besides, some other participants uttered that since they were very close to God and He loves them more, they have been subjected to this illness so as to always remember Him: "I have been through difficulties far beyond my age. But the fact that God gives more hardships to those He loves more, has made me calm." (44 years old female family member)

Some of the participants assumed their illness to be a divine test to assess their faith in God: "I didn't think that I would get cancer, but all of a sudden I caught it. Now I think it is a divine test and I hope I will pass it with flying colors." (36 years old male patient)

\section{Being cured by God's will}

The interviews showed that almost all the participants believed that they would recover if God willed so. For example, one of them said: "I had always this belief that God will give you whatever you ask of Him; and now that I want my health back, I'm sure He will give it back soon." (28 years old female patient)

Normally, they believed that their illness was according to God's command; if He wants, they will regain their health again; if not, they will die: "If I'm supposed to live in this world, I will be cured; if not, there would be nothing to regret since I have tried my best. I have faith in God." (43 years old male patient)

Some of the participants even believed that if God did not permit them to be cured, taking medication would be pointless and that the doctors are nothing more than God's agents who execute His orders: "The doctors are just God's tools; God provides these agents and puts them in our way." (50 years old female family member)

Some other participants believed in the possibility of getting cured by God's will in the form of a miracle, no matter how serious the illness is. As the daughter of a female cancer patient mentioned: "My mom is 87. She has been through 6 chemotherapy sessions in 21 days intervals. Since, she was very pious and a strong believer, upon the completion of all her 6 sessions, she said she was cured and she believed that a miracle had happened." (25 years old female family member)

In the opinion of some participants, imploring God's beloved ones (holy people and saints), who can act as mediators between the individual and God, could make their wishes come true. Giving charity in order to be healed and the recitation of supplications by the patient and their kith and kin could cause miracles.

"Imams (the Household of Prophet Mohamad (pbuh)) are like mediators and we call on to Imam Ali (pbuh) or Imam Hussein (pbuh) since we believe they have a more eminent position in God's view. We can plead them to be a mediator between God and us." (45 years old female patient) 


\section{Belief in God's supportiveness}

Some participants believed that they felt that they are shielded by God's love and support and that He is a source of energy to them: "God has proclaimed that if His love is one hundred parts, he has given ninety-nine of it to mothers. So, when a mother is ready sacrifice herself for the protection of her child, just imagine how much God loves (and protects) us." (44 year old female family member)

"Ifeel that God is higher than all things, which support us. It is true that everybody around us could help us, but it is indeed God who directs them." (33 year old male patient)

\section{Having faith in God as a relieving factor}

The interviews revealed that the majority of the participants were certain that their religious beliefs had enabled them to be pacified when dealing with difficult situations since they thought there certainly is a boon behind every difficulty from God and that it is for their own good to be in such a condition: "When you are spiritually connected, your level of tolerance goes up; even if my child is not healed and dies (God forbid!), I would not grieve as I would think it might be to my child's good." (44 year old female family member) "Whenever my religious beliefs are stronger and I have more faith in God, I feel I'm getting calmer. Much calmer"! (45 years old female patient) "If you submit your heart to God, any serious illness (even worse than ours) can be tolerated since we know that God is there and present." (50 years old female family member)

\section{Hope in divine healing}

The interviews further revealed that almost all participants considered religious beliefs as a source of hope: "When we read in the religious books that God does not disappoint any of His creatures, we get hope. I tell myself over and over that a miracle will happen sooner or later." (25 years old female family member) "My sister recites the Al-Hamd Sura (the first Sura of the Holy Quran) for me 70 times a day to ask God to help and cure me. This really gives me hope." (36 years old male patient) "God will certainly help me because I always listen to Him. So I'm sure he will listen to me as well. I'm very hopeful." (44 years old female family member)

\section{Relationship with God}

The participants' experiences indicated that they had different beliefs about their relationship with God during their illness. Some of them mentioned a strengthening and some a weakening of their faith in and relation with God after their illness; while some others mentioned that they had experienced no changes in their faith in God, and that their relationship with God would never get cut: "Relationship with God is permanent and is not something temporary." (50 years old female family member) "Sometimes, during my illness, I felt God was really close to me. I could literally feel His presence." (37 years old male patient) "I complain to God but this has never affected on my practicing my religious duties, such as saying 'daily prayers '(Namaz)." (58 years old female patient) "I used to always entrust all my work in God. I used to pray and say incantations a lot and they made me very calm. I still do these things but I feel they are not as effective as before. Maybe I don't have that previous relationship with God." (45 years old female patient)

\section{Discussion}

The present study indicated that most of the cancer patients and their families in Iran were of this religious view that their illness had occurred by the will of God. For instance, some of them considered their illness as a divine test to measure their faith in God. In this regard Nasirzadeh (Nasirzadeh and Rassolzadeh Tabatabaie, 2009), quoting Paragament (1997), suggested that during the incidence of stressful events, the individuals can attribute "what is happening" or "has happened" to God who deliberately wants to test them or teach them something (Hassankhani et al., 2010). also discovered that most of the patients under observation regarded their illness as a divine test, and believed that they had to try to pass it with distinction (Taleghani et al., 2006). Both of these studies are in agreement with this research.

Along to this belief that they had become sick according to the will of God, a belief also existed in almost all of the participants in our research that it was God who decided whether they should recover or die, whatever severe the condition of their illness was. This belief created a kind of hope in very sick patients or even in those who were battling with death since they had faith in God's kindness. In this regard, (Lynn Gall and Cornblat, 2002) reported that breast cancer survivors, who had experienced the presence of God in their lives, had a more optimistic interpretation regarding their survival .

Some other participants in this research believed that their illness was a punishment of God for their sins. (Farsi, 2007) also stated that Muslim patients consider their illness as a means of atonement of their sins. It is worth mentioning that such a belief created no negative feelings in them. However, investigations on the subjects in other cultures showed the existence of some sort of negative effects in them. Flores, 1998 stated that if negative attributes are given to God's power, i.e. if it is supposed that God has made them sick to punish them for their sins, the patients would experience larger amounts of stress (Lynn Gall and Cornblat, 2002). In addition, (Nasirzadeh and Rassolzadeh Tabatabaie, 2009) quoting an earlier study by Schafer \& Gorsuch (1991), that suggested that there is a direct relationship between the kind of cognition an individual has about God, the amount of tension he/she feels and the types of coping behaviors he/she implements. On the other hand, more positive perceptions and lower mental pressure can lead to a better utilization of solutioncentered coping strategies.

(Lynn Gall and Cornblat, 2002)A number of the participants even spoke of miracles through which, if God willed, they would recover easily, no matter how serious their illness would be. Aquino et al. (2007) revealed that owing to this belief that God can control even the worst of situations, all the patients had strong hopes of getting another chance from God (Aquino and Zago, 2007) 
Our participants also believed that invoking the saints, giving charity and reading supplications were of factors that could cause miracles to happen. In a study conducted in 2006 on breast cancer patients in Iran, Taleghani et al. cited factors such as the patients' seeking help from holy people, giving alms in charity, going on pilgrimage, and chanting supplications as aspects for coping with the illness from a religious point of view (Taleghani et al., 2006)Pargament (1997) also believed that, in dealing with stressful situations, individuals rely on their beliefs and religious activities such as prayers and supplications ((Nasirzadeh and Rassolzadeh Tabatabaie, 2009)). Also, Seyed Fatemi et al. (2006) concluded from a 1999 study by Meravigilia that supplication is an efficient adaption strategy for patients (Seyedfatemi et al., 2006)

The overall review of our findings implies that religious beliefs have positive effects on the participants' performance and mental status. Moreover, Nasirzadeh et al even goes as far as suggesting that more attention should be paid to the outstanding effect of religion on health in the fields of education and treatment, which would, consequently, lead to a big boost in improving the mental health of the society (Nasirzadeh and Rassolzadeh Tabatabaie, 2009). Additionally, Ganji et al., (2009) found a negative correlation was found between anxiety level and religious beliefs. (Ganji and Hosseini, 2010)

Another finding in our study was the fact that some participants believed that they were protected and supported by God's love and compassion, and this belief served as a source of energy for them. Maly \& Feher, in an investigation on female breast cancer patients, reported that religious belief is an important factor in the outlook of these patients. By means of relying in God, they feel more relaxed and obtain more power to further adapt with their illness (Seyedfatemi et al., 2006). Surbon (2010) too stated that, following an ambiguity about their present status and lack of trust about their future situation, many cancer patients consider their spiritual beliefs as a source of power and hope through which they can cope with their sense of fear and loneliness during all phases of their illness (Surbone and Baider, 2010).

A majority of the participants believed that their religious beliefs helped them keep their stability of mind when coping with difficult situations. Quillin et al. (2006) also reported that, to achieve relaxation, the participants made frequent use of spiritual adaptive mechanisms, specifically spiritual and religious beliefs (Quillin et al., 2006). Sligman (2000) claims that individuals who practice the religion are happier than those who do not (Rohani and Manawi pour, 2009). Lynn Gall et al, quoting from a 1990 study by Paragment, mentioned that relationship with God makes people be able to tolerate inevitable circumstances and, as a result, lowers related emotional distresses (Lynn Gall and Cornblat, 2002).

Other findings indicate that religious beliefs are a source of hope in almost all participants. Hassankhani et al concluded that the participants' religious beliefs influenced their cognition of their condition and increased their optimism for the future (Hassankhani et al., 2010) . In this regard, Lynn Gall et al suggested that religious and spiritual sources cause a general feeling of hope and
Religion as an Alleviating Factor in Iranian Cancer Patients

a positive attitude toward life(Lynn Gall and Cornblat, 2002). McClain et al also found that spiritual wellbeing can serve as an inhibitor of the hopeless feeling that often occurs in moribund patients (McClain et al., 2003).

Further, the participants' remarks showed that a kind of change had occurred in their relationship with God following their illness such that they seemed more inclined toward God. Lynn Gall et al states that researchers emphasizes on the importance of relationship with God as an aspect of spirituality, which may provide a kind of hope, optimistic view, and an inner power to adapt with stresses (Lynn Gall and Cornblat, 2002).

The findings of this research also showed that the majority of participants had religious beliefs, which gave them a feeling of power, hope, peace and trust. Abdoli et al. assessed the effect of fatalistic beliefs in Iranian Muslim patients as positive effect (Abdoli et al., 2011) .Here, another significant point is that along with these religious beliefs, the patients resolutely pursued their treatment processes by any possible way: be it surgery, chemotherapy or radiotherapy. It implies that although these beliefs were fatalistic in nature, they did not create any interruption in their therapeutic process Fasihi Harandi et al also reported that although all the participants attributed their illness to God's will, they were incessantly pursuing their treatment process (Harandy et al., 2009) , which is in consistence with the results of the present study. On the other hand, Yvonne Talbert suggested that fatalistic beliefs have a significantly negative relationship with the patients' acceptance of breast cancer screening (Talbert, 2008). Nasirzadeh et al , quoting Spika (2003), suggested that coping strategies using religious beliefs and principles can be useful and can, in fact, serve as a shortcut by which people can utilize new strategies to solve their problems; however, if an individual avoids actively coping with his/her problems and just waits for God to improve his/her situation, a kind of religious malfunctioning takes shape (Nasirzadeh and Rassolzadeh Tabatabaie, 2009). Our findings in the present study further illustrated that religion has had a positive outcome in almost all the participants. This may be partly due to the integration of many religious beliefs and principles in the Iranian spirit and culture, resulting in the acceptance of the illness and coping with it. Similarly, 2009 research on Iranian cancer patients, (Rezaei et al., 2009)reported that, due to their cultural background, Iranians are generally religious in nature and they lean toward religion in time of . Taleghani et al also suggested that many of the breast cancer patients accepted their illness as a divine fate created by God's will and they had to surrender to it (Taleghani et al., 2006). Asadi-Lari et, in a review study, entitled, "An Evaluation of the Way of Extending Spiritual Care Services in Islamic Societies", found that in the majority of the researches they had analyzed, cancer patients who had religious beliefs had shown better adaptive strategies to deal with their situations (Asadi et al., 2012) .

In conclusion, the experiences of the patients and their families participating in this study showed that relationship with God and religious beliefs had a positive effect on their accepting and coping with the illness. It not only had not led to any negative results on them such as 
Mozhgan Rahnama et al

stopping the treatment process or just waiting for being healed by God, but, in fact, their trust in God had resulted in an increased hope of being cured and a continuation of the medication, no matter how grave their illness was. It means that the effects of these religious beliefs can be evaluated as positive; and enhancing such beliefs through religious counseling can be prescribed as a coping strategy for such patients to adapt to their situations.

\section{References}

Abdoli S, Ashktorab T, Ahmadi F, et al (2011). Religion, faith and the empowerment process: Stories of Iranian people with diabetes. Int J Nurs Pract, 17, 289-98.

Aquino VV,Zago MMF (2007). The meaning of religious beliefs for a group of cancer patients during rehabilitation. Rev Lat Am Enfermagem, 15, 42-7.

Asadi Lari M, Goushegir S, Madjd Z, et al (2012). Spiritual care at the end of life in the Islamic context, a systematic review. Iran J Cancer Prev, 1, 63-7.

Ebadi A, Ahmadi F, Ghanei M, et al (2009). Spirituality: A key factor in coping among Iranians chronically affected by mustard gas in the disaster of war. Nurs Health Sci, 11, 344-50.

Farsi Z, Salsali, M (2007). Concept of care and nursing met paradigm in Islam. Teb \& Tazkiye, 16, 8-21.

Ganji T, Hosseini AF (2010). Spirituality and anxiety in nursing students of faculty of nursing and midwifery iran university of medical science -2006. Iran Journal of Nursing (IJN), 23, 44-51.

Harandy TF, Ghofranipour F, Montazeri A, et al (2009). Muslim breast cancer survivor spirituality: coping strategy or health seeking behavior hindrance? Health care for women international, 31, 88-98.

Hassankhani H, Taleghani F, Mills J, et al (2010). Being hopeful and continuing to move ahead: religious coping in Iranian chemical warfare poisoned veterans, a qualitative study. $J$ Relig Health, 49, 311-21.

Heiydari S, Salahshorian A, Rafie F, et al (2008). Correlation of perceived social support and size of social network with quality of life dimension in cancer patients. J Kashan Univ Med Sci, 12, 15-22.

Lynn Gall T, Cornblat MW (2002). Breast cancer survivors give voice: a qualitative analysis of spiritual factors in long term adjustment. Psychooncology, 11, 524-35.

McClain CS, Rosenfeld B, Breitbart W (2003). Effect of spiritual well-being on end-of-life despair in terminally-ill cancer patients. The Lancet, 361, 1603-7.

Montaseri S, Sharif $f$ (2008). Investigating the physical and psychological problems in children of parents with cancer. J Qazvin Univ Med Sci, 2, 26-31.

Mueller PS, Plevak DJ, Rummans TA. Religious involvement, spirituality, and medicine: implications for clinical practice. Mayo clinic proceedings, 2001. Elsevier, 1225-35.

Nasirzadeh R, Rassolzadeh Tabatabaie K (2009). Religious beliefs and coping strategies in students. Hormozgan Med $J$, 15, 36-45.

Powe BD (1997). Cancer fatalism-Spiritual perspectives. J Relig Health, 36, 135-44.

Quillin JM, McClish DK, Jones RM, et al (2006). Spiritual coping, family history, and perceived risk for breast cancercan we make sense of it? J Genet Couns, 15, 449-60.

Rezaei M, Seyedfatemi N, Hosseini F (2009). Spiritual wellbeing in cancer patients who undergo chemotherapy. Hayat, 14, 33-9.

Rohani A, Manawi pour D (2009). Relationship between religious practice with happiness and marriage satisfaction in Islamic Azad University of Mobarake. Knowledge \& research in applied psychology, 0, 189-206.

Rustoen T, Schjolberg TK, Wahl AK (2003). What areas of cancer care do Norwegian nurses experience as problems? $J$ Adv Nurs, 41, 342-50.

Seyedfatemi N, Rezaei M, Givari A, et al (2006). Prayer and spiritual well-being in cancer patients. Payesh Health Monit, 5, 295-303.

Strubert Speziale H, Alen J, Carpenter D (2003). Qualitative research in nursing. Third Editionth edition. Philadelphia: Williams \& Wilkings Co.

Surbone A, Baider L (2010). The spiritual dimension of cancer care. Crit Rev Oncol Hemat, 73, 228-35.

Talbert PY (2008). The relationship of fear and fatalism with breast cancer screening among a selected target population of African American middle class women. J Soc Behav Health Sci, 2, 96-110.

Taleghani F, Parsa-yekta Z, Nikbakht Nasrabadi A (2006). Coping with breast cancer in newly diagnosed women: A qualitative study. Iran J Psychiatry Clin Psychol, 12, 282-8. 